\title{
Evaluation of Training Requirements in Patients Undergoing Breast Surgery
}

\author{
ASENA TOPUZ ${ }^{1}$, ZEHRA DURNA², and GAMZE TEMIZ ${ }^{3}$ \\ ${ }^{1}$ Affiliation not available \\ ${ }^{2}$ TC Demiroglu Bilim University \\ ${ }^{3}$ Saglik Bilimleri Universitesi
}

July 17,2020

\begin{abstract}
Objective: This study was conducted to evaluate the educational needs in patients undergone breast surgery. Material and Methods: The data of this descriptive study were collected from 67 patients who underwent breast surgery between June 15 , 2018 and August 15, 2018 in two private hospitals on the European side. After obtaining institutional permission and ethics committee approval, data were collected using the "Patient Learning Needs Scale" and "Patient Information Form" prepared by the researcher and analyzed statistically. Results: The mean age of the patients included in the study was $45.04 \pm 8.039$, and $79.1 \%$ was married, $32.8 \%$ was college or university graduate, and $82.1 \%$ had a balanced income. It was found that $35.8 \%$ of the patients had a history of breast disease in their family, $97 \%$ had surgical treatment, and $98.5 \%$ had been informed before the surgery. It was observed that $82.1 \%$ of the patients considered the information given adequate. It was determined that patients were in need of learning more about medications and quality of life (4.76 \pm 0.430$)$. No statistically significant relationship was found between the learning needs and the age, marital status, and educational status of the patients. Conclusion: It may be suggested that the trainings for patients who undergone breast surgery should be planned in line with the needs.
\end{abstract}

\section{Hosted file}

MANUSCRIPT.DOCX available at https://authorea.com/users/343686/articles/470315-evaluation-oftraining-requirements-in-patients-undergoing-breast-surgery

\section{Hosted file}

TABLES-EN.DOCX available at https://authorea.com/users/343686/articles/470315-evaluation-oftraining-requirements-in-patients-undergoing-breast-surgery 